\title{
Research on the Relationship between Online Shopping Experience and Consumer Impulse Buying
}

\author{
Yang Liu ${ }^{\text {a }}$, Yihe Zhang, Chunyan Qiu, ${ }^{\text {b** }}$ and Yan Ma \\ School of Management Science and Information Engineering, Jilin University of Finance and Economics, \\ Changchun, 130117, China \\ a email: 7923759@qq.com, bemail: 81692002@qq.com \\ *Corresponding author
}

Keywords: Online shopping experience, Impulse Buying, Emotional response, shopping platform

\begin{abstract}
Studying the impact of online shopping experience on consumer impulse buying behavior is of great significance to the development of shopping platforms and merchant marketing strategies. Based on the SOR model and the online shopping environment, this paper studies the relationship between consumers' shopping experience and impulsive buying behavior and the influencing mechanism under the online shopping situation. The online shopping experience is divided into sensory experience, cognitive experience, practical experience and relationship experience, and the research model of the influence factors of online shopping experience on consumer impulse buying behavior is constructed. Data were collected through questionnaires, and statistical analysis and hypothesis testing were performed using SPSS and Smart PLS. The study found that the sensory experience of the online shopping experience significantly affects consumers' awakening mood, sensory experience, cognitive experience and practical experience significantly marketing consumer pleasure, awakening the perception of pleasure that significantly affects consumers, and significantly affecting consumers together with consumer pleasure and the impulsive buying behavior.
\end{abstract}

\section{Introduction}

Whether in a physical shopping environment or a virtual shopping environment, the consumer experience has become an important part of people's lives and consumption. The consumer experience has a direct impact on consumer satisfaction, loyalty and willingness to pay attention, so experiential marketing It has gradually become a hot spot for retail companies. In the online shopping environment, consumers interact with the shopping platform through the shopping software, and the process of browsing, purchasing, and enjoying the online service generates an online experience. Some scholars have proved that seeking experience has become one of the motivations for consumers to shop online. In the online shopping experience, consumers will have different feelings in terms of sensory, cognition, practicality and relationship interaction, which will have a certain impact on their emotional response. Previous studies have shown that emotional response is the main factor that causes impulse purchase, which is divided into pleasure perception and arousal perception. In the shopping experience process, the consumer's emotional perception also produces impulsive buying behavior.

Therefore, this paper takes the online shopping environment as the research background, and studies the relationship between the consumer shopping experience and the impulse buying behavior in the online shopping situation, and believes that the online shopping experience process will stimulate consumers to react and generate impulse buying behavior. Construct a research model of the influencing factors of online shopping experience on consumer impulse buying behavior. Data were collected through questionnaires, and empirical analysis and hypothesis testing were conducted to draw conclusions. The research results are of great significance for improving the online shopping experience and the marketing strategy of the merchants. 


\section{Theoretical Basis and Literature Review}

The consumer experience refers to the emotional perception that the consumer experiences in the consumption process to satisfy the emotional needs of personalized consumption in the scene provided by the enterprise. The pursuit of pleasure is the goal and the consumer experience is performed in an interactive manner [5]. The experience is based on the overall feelings of consumers. It is a multi-dimensional structure composed of various basic elements, which is reflected in the senses, emotions, cognition and actions [6]. Here, we believe that the online shopping experience refers to the emotional perception that consumers experience in the shopping process to satisfy their emotional needs. It is a multi-dimensional, personalized internal mental state. Online shopping is more virtual than traditional shopping, so the shopping experience process is more complicated. Based on the research of predecessors, Pentina divides the online shopping experience into five kinds through exploratory analysis, which are sensory experience, cognitive experience, practical experience, relationship experience and sense of belonging and interactive experience [7]. He Heping conducted a research on the online shopping experience, and believed that some of the items in the interactive experience are similar to the relationship experience. The other part of the test is similar to the practical experience. Therefore, the online shopping experience is divided into sensory experience, cognitive experience, practical experience and the relationship experiences four dimensions [8]. Based on this, this paper divides the online shopping experience into four dimensions, and studies the emotional response and the impact mechanism on impulse buying behavior during the shopping experience.

\section{Model Construction and Research Hypothesis}

According to the previous analysis, consumers will experience different dimensions in the process of online shopping experience, which will have an impact on emotional response, and it is easy to generate impulsive buying behavior. Therefore, based on the previous research, this paper builds a research model of the impact of online shopping experience on consumer impulse buying behavior based on SOR theory, as shown in Figure 1. The online shopping experience is divided into four dimensions: sensory experience, cognitive experience, practical experience and relationship experience. Through the experience process, consumers are stimulated to generate internal emotional reactions, including pleasure perception and arousal sensibility, which in turn affects consumers' impulse buying behavior.

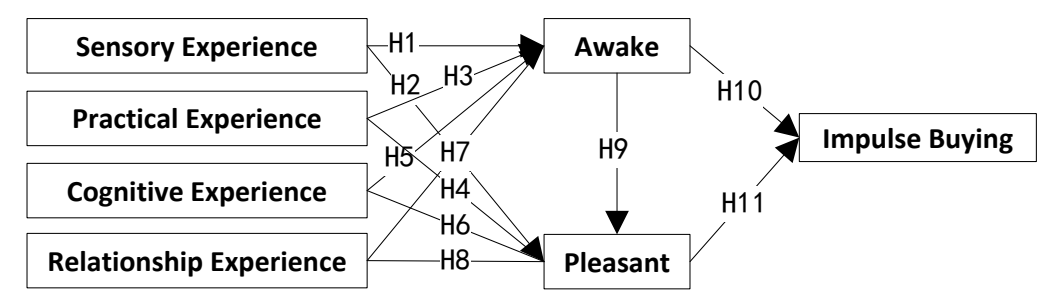

Figure 1 Research model of the impact of online shopping experience on consumer impulse buying behavior

Consumer experience theory regards the online shopping experience as a multi-dimensional, personalized internal mental state [7]. Among them, the shopping experience can be divided into four dimensions, namely sensory experience, cognitive experience, practical experience and relationship experience. Sensory experience refers to the beauty of the consumer through visual and auditory [8], mainly reflected in the visual elements of the shopping platform during the online shopping, such as the dynamic video of the product, the image display effect of the product, etc., and the hearing in the shopping platform. Elements, such as background music, audio effects, etc., give consumers a subjective feeling; Cognitive experience refers to the experience that helps consumers solve the purchase problem [8], which is mainly reflected in the preferential strength of the shopping platform, marketing strategy, personalized service, personalized recommendation, etc. The subjective feelings 
brought to consumers by the function of knowing; Practical experience refers to the ease of use of the interface for achieving shopping goals [8], mainly reflected in the online shopping period, the navigation system of the shopping platform, the search engine of the product, the collection function, etc., which reflect the ease of use of the online shopping platform, etc. The subjective feelings that related functions bring to consumers; Relationship experience refers to the relationship with other shoppers [8], which is mainly reflected in the subjective feelings that consumers bring to consumers through the online shopping process and the relationship established by merchants or other consumers. Consumers will have a certain emotional or cognitive response during the shopping experience. Therefore, the research hypothesis is proposed.

H1: The sensory experience process significantly positively affects the consumer's arousal.

H2: The sensory experience process significantly positively affects the consumer's enjoyment.

H3: The cognitive experience process significantly positively affects consumers' arousal.

H4: The cognitive experience process significantly positively affects the consumer's pleasure.

H5: The practical experience process significantly positively affects consumers' arousal.

H6: The practical experience process significantly positively affects the consumer's enjoyment.

H7: The relationship experience process significantly positively affects the consumer's arousal.

H8: The relationship experience process significantly positively affects the consumer's enjoymen.

Emotion is an individual's temporary, strong emotional response to all current stimuli and behavioral interpretation [3]. Mehrabian and other studies have shown that stimuli can trigger an individual's emotional response, which in turn promotes tendencies or evasive behavior [1]. In consumer behavior, pleasure and awakening are the main reactions of consumers to external stimuli [3]. Awakening refers to the degree to which an individual feels stimulating, excited, excited, and pleasantly surprised in a particular situation; pleasure refers to the degree to which a person feels satisfied, happy, happy, and comfortable in a particular situation [2]. Empirical studies by Rafaeli et al. have shown that a high degree of vitality evokes a positive effect on pleasure [3]. Therefore, the arousal is closely related to pleasure, that is, the higher the arousal of the consumer, the stronger the pleasure will be. Therefore, we also believe that in the online shopping situation, the consumer's arousal can significantly affect the consumer's perception of pleasure. In the online shopping experience, sensory experience, cognitive experience, practical experience and relationship experience will stimulate consumers' emotional response to a certain extent, including arousing emotions and pleasures, thus affecting consumers' impulse shopping behavior. The stronger the consumer's arousal and pleasure perception, the more likely the consumer impulse shopping behavior to occur. Therefore, the following assumptions are made.

H9: The awakening mood of consumers in the online shopping experience significantly positively affects the mood of pleasure.

H10: The wake-up mood of consumers in the online shopping environment significantly positively affects impulse buying behavior.

H11: Consumers' pleasure in the online shopping environment significantly positively affects impulse buying behavior.

\section{Research Design and Empirical Analysis}

\subsection{Questionnaire design and variable measurement}

This paper mainly uses the questionnaire survey method to refer to the previous research design questionnaire. The questionnaire consists of three parts. The first part is the basic descriptive information of the questionnaire. The second part mainly investigates sample statistics. The third part is the measure of latent variables such as online shopping experience, emotional response and impulse purchase. There are 7 latent variables. The measurement of latent variables refers to the research results of the predecessors, and the measurement items of some variables are further supplemented and developed through interviews. Among them, the online shopping experience and its four dimensions mainly refer to the research of PENTINA [7]. The arousal and pleasant response 
of the emotional part mainly refer to the research of Koo [9], and the impulse buying behavior mainly refers to the research of Verhagen [4]. Through the results of the pre-study feedback, the questions are appropriately deleted and revised, and a final questionnaire is formed.

\subsection{Data collection and statistical analysis}

The questionnaire was distributed and collected using Questionnaire Star Software, and 450 copies were distributed and collected through online and offline methods. The remaining 385 were valid. The effective rate of the questionnaire was $85.5 \%$. Through statistical analysis of valid questionnaire data, $58.4 \%$ of the participants in the questionnaire survey were women, and $41.6 \%$ were men; The education level is mainly concentrated on undergraduate and postgraduate education, accounting for $82.9 \%$ of the overall sample; The age is mainly concentrated in 18-45 years old, accounting for $91.5 \%$ of the overall sample; The online shopping experience of the respondents was mainly over one year, accounting for $97.9 \%$ of the overall sample, as shown in Table 1.

Table 1: Sample description statistics (385)

\begin{tabular}{|c|c|c|c|c|c|c|c|}
\hline Option & $\begin{array}{l}\text { Range of } \\
\text { options }\end{array}$ & Frequency & $\begin{array}{c}\text { Percentage } \\
(100 \%)\end{array}$ & Option & Range of options & Frequency & $\begin{array}{l}\text { Percentag } \\
\text { e }(100 \%)\end{array}$ \\
\hline \multirow[t]{2}{*}{ Sex } & Male & 160 & 41.56 & \multirow{4}{*}{$\begin{array}{l}\text { Education } \\
\text { level }\end{array}$} & $\begin{array}{l}\text { High school and } \\
\text { below }\end{array}$ & 10 & 2.597 \\
\hline & Female & 225 & 58.44 & & Specialist & 56 & 14.55 \\
\hline \multirow{6}{*}{ Age } & $\begin{array}{l}\text { Under } 18 \text { years } \\
\text { old }\end{array}$ & 18 & 4.67 & & Bachelor & 235 & 61.04 \\
\hline & 18-24 years old & 139 & 36.1 & & $\begin{array}{l}\text { Graduate and } \\
\text { above }\end{array}$ & 84 & 21.82 \\
\hline & 25-35 years old & 128 & 33.25 & \multirow{4}{*}{$\begin{array}{c}\text { Online } \\
\text { shopping } \\
\text { experience }\end{array}$} & Within 1 year & 8 & 2.07 \\
\hline & $36-45$ years old & 85 & 22.08 & & $1-3$ years & 105 & 27.27 \\
\hline & $46-60$ years old & 15 & 3.89 & & 3-5 years & 132 & 34.29 \\
\hline & $\begin{array}{l}60 \text { years old and } \\
\text { above }\end{array}$ & 0 & 0 & & More than 5 years & 140 & 36.36 \\
\hline
\end{tabular}

\subsection{Reliability and Validity Test}

This paper uses the SPSS and Smart PLS software for reliability and validity analysis. Through SPSS test, the overall reliability of the questionnaire was Cronbach's $\alpha=0.831$, indicating that the overall reliability of the questionnaire was higher; $\mathrm{KMO}=0.812$, indicating that it is suitable for factor analysis. As shown in Table 2, the CR combination reliability and Cronbach's $\alpha$ of each latent variable in the sample are greater than 0.7 , indicating that the questionnaire has good reliability and internal consistency. Validity testing is mainly through polymerization validity and discriminant validityIt can be seen from Table 2 that the AVE of each latent variable is greater than 0.5 , and the scale is considered to have good polymerization validity. The test of discriminant validity is measured by comparing the square root of each factor AVE with the correlation coefficient between variables. When the square root of AVE value is greater than the correlation coefficient between variables, it indicates that the discriminant validity is better. As shown in Table 3, the diagonal is the square root of each variable AVE, and the rest are correlation coefficients. The square root of AVE in the table is greater than the correlation coefficient, indicating that the sample has good discriminant validity.

\subsection{Hypothesis Testing}

In this paper, the structural equation model is constructed by Smart PLS, path analysis and hypothesis testing are performed. $\mathrm{R}^{2}$ mainly reflects the degree of interpretation of the explanatory variables to the explained variables, the path analysis results, the significance level and $\mathrm{R} 2$ are shown in Figure 2. The sensory experience of the online shopping platform is positively affecting consumers' awakening mood, explaining $34.6 \%$ of wake-up; The sensory experience, practical experience and cognitive experience and awakening markedly evoke positive consumer sentiment, explaining $56.9 \%$ of pleasure; wake-up and pleasure significantly positively impacted impulse 
buying behavior, explaining 19.3\% of impulse buying.

Table 2: Mean, Factor load, Cronbach’s Alpha, CR and AVE value

\begin{tabular}{|c|c|c|c|c|c|c|c|}
\hline Factor & Index & Average value & Standard deviation & Standard load & Cronbach's $\alpha$ & $\mathbf{C R}$ & AVE \\
\hline \multirow{4}{*}{$\begin{array}{l}\text { Sensory experience } \\
\text { ( SE) }\end{array}$} & SE1 & 3.195 & 0.790 & 0.849 & \multirow{4}{*}{0.853} & \multirow{4}{*}{0.901} & \multirow{4}{*}{0.695} \\
\hline & SE2 & 2.940 & 0.882 & 0.817 & & & \\
\hline & SE3 & 3.081 & 0.829 & 0.870 & & & \\
\hline & SE4 & 2.982 & 0.842 & 0.796 & & & \\
\hline \multirow{4}{*}{$\begin{array}{l}\text { Practical experience } \\
\text { ( PE ) }\end{array}$} & PE1 & 3.517 & 0.819 & 0.822 & \multirow{4}{*}{0.880} & \multirow{4}{*}{0.918} & \multirow{4}{*}{0.736} \\
\hline & PE2 & 3.584 & 0.834 & 0.897 & & & \\
\hline & PE3 & 3.631 & 0.808 & 0.867 & & & \\
\hline & PE4 & 3.623 & 0.829 & 0.844 & & & \\
\hline \multirow{4}{*}{$\begin{array}{l}\text { Cognitive experience } \\
\text { ( CE ) }\end{array}$} & CE1 & 3.745 & 0.771 & 0.869 & \multirow{4}{*}{0.837} & \multirow{4}{*}{0.890} & \multirow{4}{*}{0.669} \\
\hline & CE2 & 3.610 & 0.824 & 0.777 & & & \\
\hline & CE3 & 3.740 & 0.735 & 0.780 & & & \\
\hline & CE4 & 3.738 & 0.739 & 0.840 & & & \\
\hline \multirow{3}{*}{$\begin{array}{l}\text { Relationship experience } \\
\text { ( RE ) }\end{array}$} & RE1 & 3.761 & 0.834 & 0.725 & \multirow{3}{*}{0.731} & \multirow{3}{*}{0.801} & \multirow{3}{*}{0.575} \\
\hline & RE2 & 3.527 & 0.796 & 0.855 & & & \\
\hline & RE3 & 3.151 & 0.936 & 0.706 & & & \\
\hline \multirow{4}{*}{$\begin{array}{l}\text { Awake } \\
\text { ( AR ) }\end{array}$} & AR1 & 2.997 & 0.804 & 0.861 & \multirow{4}{*}{0.898} & \multirow{4}{*}{0.929} & \multirow{4}{*}{0.767} \\
\hline & AR2 & 3.119 & 0.881 & 0.902 & & & \\
\hline & AR3 & 3.052 & 0.872 & 0.913 & & & \\
\hline & AR4 & 3.127 & 0.839 & 0.825 & & & \\
\hline \multirow{4}{*}{$\begin{array}{l}\text { Pleasant } \\
\text { ( HAP ) }\end{array}$} & HAP1 & 3.330 & 0.775 & 0.839 & \multirow{4}{*}{0.822} & \multirow{4}{*}{0.882} & \multirow{4}{*}{0.657} \\
\hline & HAP2 & 3.312 & 0.777 & 0.892 & & & \\
\hline & HAP3 & 3.345 & 0.778 & 0.887 & & & \\
\hline & HAP4 & 3.483 & 0.783 & 0.786 & & & \\
\hline \multirow{3}{*}{$\begin{array}{l}\text { Impulse shopping } \\
\text { ( MP ) }\end{array}$} & MP1 & 3.294 & 0.789 & 0.814 & \multirow{3}{*}{0.822} & \multirow{3}{*}{0.894} & \multirow{3}{*}{0.738} \\
\hline & MP2 & 3.452 & 0.916 & 0.885 & & & \\
\hline & MP3 & 3.462 & 0.908 & 0.877 & & & \\
\hline
\end{tabular}

Table 3: Discriminant validity analysis

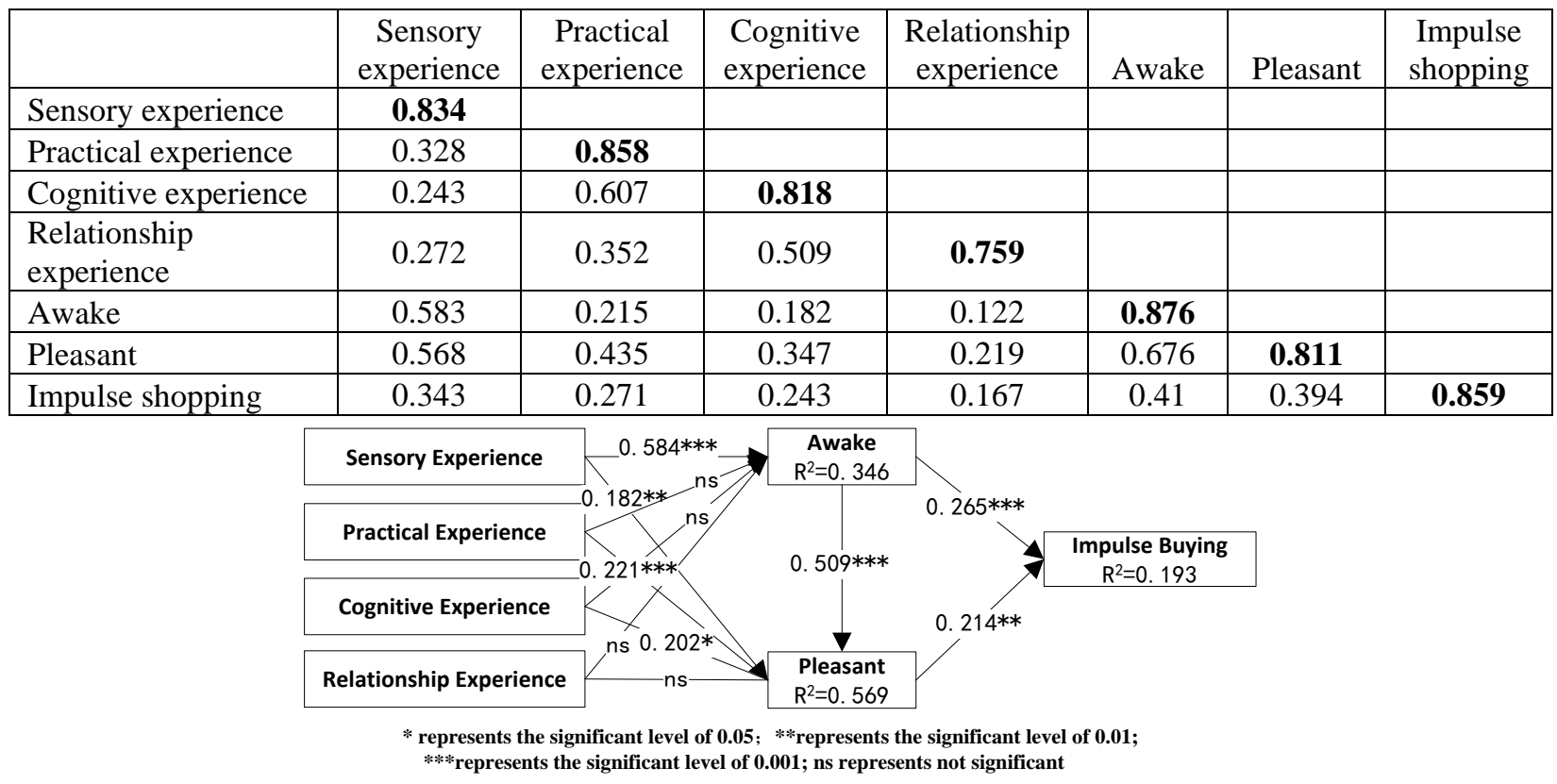

Figure 2: The path coefficient of research model and its significant level 


\subsection{Research Results and Discussion}

In order to study the influence of online shopping experience on consumer emotional response and impulse buying behavior, this paper builds a research model based on SOR theory. The empirical analysis results are shown in Table 4. It is assumed that H3, H5, H7 and H8 are not supported, and other hypotheses are obtained.

Table 4: Summary of research results

\begin{tabular}{|c|c|c|c|c|}
\hline $\begin{array}{c}\text { Hypothesi } \\
\text { s }\end{array}$ & Path relationship & T value & $\begin{array}{c}\text { Coefficient and } \\
\text { significance }\end{array}$ & Research result \\
\hline H1 & Sensory experience $\rightarrow$ Awake & 10.192 & $0.584^{* * *}$ & Support \\
\hline H2 & Sensory experience $\rightarrow$ Pleasure & 3.182 & $0.182^{* *}$ & Support \\
\hline H3 & Practical experience $\rightarrow$ Awake & 0.055 & ns & Not support \\
\hline H4 & Practical experience $\rightarrow$ Pleasure & 4.069 & $0.221^{* * *}$ & Support \\
\hline H5 & Cognitive experience $\rightarrow$ Awake & 1.134 & ns & Not support \\
\hline H6 & $\begin{array}{c}\text { Cognitive experience } \rightarrow \\
\text { pleasure }\end{array}$ & 1.539 & $0.202^{*}$ & Support \\
\hline H7 & $\begin{array}{c}\text { Relationship experience } \rightarrow \\
\text { Awake }\end{array}$ & 1.333 & $\mathrm{~ns}$ & Not support \\
\hline H8 & $\begin{array}{c}\text { Relationship experience } \rightarrow \\
\text { pleasure }\end{array}$ & 0.262 & $\mathrm{~ns}$ & Support \\
\hline H9 & Awake $\rightarrow$ pleasure & 10.902 & $0.509^{* * *}$ & Support \\
\hline H10 & Awake $\rightarrow$ Impulse Shopping & 3.806 & $0.265^{* * *}$ & Support \\
\hline H11 & Pleasant $\rightarrow$ Impulse Shopping & 2.862 & $0.214^{* *}$ & . \\
\hline
\end{tabular}

The sensory experience in the online shopping experience significantly affects the consumer's arousal and pleasure, and its impact on the arousal is very significant. The T value reaches 10.192, and the impact on the pleasure is also significant. The online shopping platform can display goods through virtual reality technology, enhance the effect of product images, dynamic video effects, and trigger the immersive feelings of consumers with music melody, through entertainment activities, such as "grabbing red packets" and "scrapping gold coins". Waiting to awaken consumers' shopping enthusiasm and increase the consumer's sensory experience, which in turn leads consumers to make shopping behaviors in a relaxed and enjoyable shopping experience.

The cognitive experience in the online shopping experience significantly affects consumer pleasure, but has no significant effect on arousal. The research results show that the online shopping platform's preferential strength, marketing strategy, personalized service, personalized recommendation and other cognitive functions related to consumers' purchase of goods can bring consumers a certain sense of subjective feelings. And happy emotional reactions, but did not directly stimulate consumers to produce exciting, exciting emotional reactions. Therefore, the online shopping platform should adopt the corresponding marketing strategy in the consumer online shopping process cognitive experience to further improve the consumer cognitive experience process.

The practical experience in the online shopping experience significantly affects the consumer's pleasure, but the impact on the awakening mood is not significant. The research results show that the navigation system, search engine, and collection function of the online shopping platform reflect the subjective feelings brought by the relevant functional attributes such as the ease of use of the online shopping platform, which can make the consumers have a certain satisfaction. Happy emotional response, but did not directly stimulate consumers to produce exciting, exciting emotional reactions. Therefore, the online shopping platform should be further improved in the process of consumer online shopping practical experience, enhancing the ease of use and practicability of the platform.

The relationship experience in the online shopping experience has no significant impact on consumer pleasure and arousal. The results of the study show that in the online shopping process, the relationship established by consumers with merchants or other consumers does not subjectively generate emotional or emotional reactions to consumption. In online shopping, the shopping process is generated in a virtual environment, and the relationship experience is reflected by the interaction 
between the shopping platform and the consumer, the merchant and the consumer, and the consumer and the consumer, so the merchant should be in the online shopping process. In order to fully enhance the interaction with consumers and enhance the consumer experience.

Consumer awakening significantly positively affects the consumer's perception of pleasure, and both awakening and pleasure significantly affect the consumer's impulse buying behavior. The sensory experience, cognitive experience and practical experience in the shopping experience affect the awakening and pleasure of consumers to varying degrees. The higher the emotion, the stronger the pleasure will be. The strong emotional reaction will directly affect the consumer's impulse buying behavior. In turn, it affects impulse buying behavior.

\section{Research conclusion and prospect}

Based on the SOR theory, this paper divides the online shopping experience into sensory experience, cognitive experience, practical experience and relationship experience, and constructs a research model of online shopping experience and consumer impulse shopping behavior. Data were collected through questionnaires for statistical analysis and hypothesis testing. The study found that the sensory experience of the online shopping experience significantly affects consumers' awakening mood, sensory experience, cognitive experience and practical experience significantly marketing consumer pleasure, awakening the perception of pleasure that significantly affects consumers, and significantly affecting consumers together with consumer pleasure Impulsive buying behavior.

This paper focuses on the impact of four aspects of online shopping experience on consumer emotional response and impulse buying behavior. In the future research, we can introduce shopping motivation, shopping value, shopping environment and other factors to develop a system for consumer shopping behavior.

\section{Acknowledgments}

This paper is supported by the Changchun City Philosophical and Social Science Planning Project "Research on the Measurement of Public Happiness and Its Influencing Factors in Changchun City”(No. CSKT2018ZX-010) And Jilin University of Finance and Economics Doctoral Fund Project "Research on User Privacy Information Disclosure Behavior and Protection Mechanism in Online Medical Health Service”(No. 2018B15).

\section{References}

[1] Mehrabian, Russell. An Approach to Environmental Psychology, MA, Cambrige: MIT Press, 1974.

[2] WU J F, CHANG Y P, HOU D L. The Influence of Online Store Image on Emotional Response and Online Impulsive Purchase Intention[J]. Business Economics and Management, 2012(08): 35-44.

[3] Rafaeli E, Revelle W. A premature consensus: are happiness and sadness truly opposite affects? [J]. Motivation and Emotion,2006,30(1): 1- 12.

[4] Verhagen T, Van Dolen W. The influence of online store beliefs on consumer online impulse buying: A model and empirical application [J]. Information \& Management, 2011, 48 (8): 320-327.

[5] WANG T, CUI G H. Interpretation and Construction of Experience Marketing under the Background of Economic Form Evolution [J]. Economic Management, 2003(20): 43-49.

[6] YANG J H. An Empirical Study of the Impact of Consumer Experience on Retailer Brand Assets[J]. Journal of Jinan University(Philosophy and Social Sciences),2015,37(12):38-47+1

[7] Pentina I, Amialchuk A, Taylor D G. Exploring Effects of online Shopping Experiences on Browser Satisfaction and EtailPerformance [J]. International Journal of Retail \& Distribution Management, 2011, 39( 10) : 742-758. 
[8] HE H P, ZHOU Z M. Research on Online Shopping Value Based on Consumer Experience [J]. Business Economics and Management, 2013(03): 63-72.

[9] Koo D M, Ju S H. The interactional effects of atmospherics and perceptual curiosity on emotions and online shopping intention [J]. Computers in Human Behavior, 2010, 26(3):377-388. 